\title{
PROMOÇÃO DE SAÚDE BUCAL EM PACIENTES COM NECESSIDADES ESPECIAIS DO MUNICÍPIO DE CERRO AZUL-PR
}

Larissa Carvalho TROJAN, Mônica Carmem JUNKES, Rafael Gomes DITTERICH, Cristhiane Aparecida MARIOT, Marilene da Cruz Magalhães BUFFON

O município de Cerro Azul-PR está situado na região do Vale do Ribeira, localidade com um dos menores IDH (Índice de Desenvolvimento Humano)_do estado. Por meio de um acordo entre o município de Cerro Azul-PR e o curso de Odontologia da UFPR (Universidade Federal do Paraná), os acadêmicos tiveram a oportunidade de avaliar as condições de saúde bucal de escolares e planejar ações de promoção à saúde. No ano de 2006, a população avaliada compreendeu os alunos portadores de necessidades especiais do município. Em vista do alto índice de cárie foram coletadas três amostras de água, no qual constatou concentrações de flúor muito baixas ( 0,23 a 0,46 ppm de flúor). Também foi verificada uma alta prevalência de doença periodontal. Entre as atividades realizadas estão: palestras educativas, orientação supervisionada de higiene bucal, distribuição de kits para a higiene oral e procedimentos clínicos preventivos. O projeto tem como objetivo proporcionar ao acadêmico o reconhecimento da realidade local e da relação entre a condição de vida e seus agravos à saúde bucal, bem como, de realizar e organizar ações em saúde bucal para pacientes com necessidades especiais. 